\title{
Descriptive epidemiology of injuries in a Brazilian premier league soccer team
}

This article was published in the following Dove Press journal:

Open Access Journal of Sports Medicine

26 June 2013

Number of times this article has been viewed

\section{Rafael Júlio de Freitas \\ Guina Fachinal,2 \\ Marília dos Santos Andrade ${ }^{3}$ \\ Fernando Roberto Silva ${ }^{4}$ \\ Silas Waszczuk-Junior ${ }^{4}$ \\ Paulo César Montagner ${ }^{\prime}$ \\ João Paulo Borin' \\ Claudio Andre Barbosa de \\ Lira $^{5}$ \\ 'Departamento de Ciência do \\ Esporte, Faculdade de Educação \\ Física, Universidade Estadual de \\ Campinas (UNICAMP), Campinas, \\ Brazil; ${ }^{2}$ Confederação Brasileira de \\ Basketball (CBB), Rio de Janeiro, \\ Brazil; ${ }^{3}$ Departamento de Fisiologia, \\ Universidade Federal de São Paulo, \\ São Paulo, Brazil; ${ }^{4}$ Grêmio Barueri \\ Futebol LTDA, Barueri, Brazil; ${ }^{5}$ Setor \\ de Fisiologia Humana e do Exercício, \\ Universidade Federal de Goiás, \\ Câmpus Jataí, Jataí, Brazil}

Correspondence: Claudio Andre Barbosa de Lira

Setor de Fisiologia Humana e do

Exercício, Universidade Federal

de Goiás, Câmpus Jataí - Unidade Jatobá,

BR 364, km 192, 3800 Parque Industrial,

Jataí 7580 I-6I5, GO, Brazil

Tel +55643606830I

Email andre.claudio@gmail.com

\begin{abstract}
Soccer, which has a large number of participants, has a high injury incidence that causes both financial and time burdens. Therefore, knowledge about the epidemiology of soccer injuries could allow sports-medicine professionals, such as physicians and physiotherapists, to direct their work in specific preventive programs. Thus, our aim was to conduct an epidemiological survey of injuries sustained by professional soccer players from the same team who participated in the Brazilian championship premier league in 2009. To this end, we evaluated retrospectively player medical records from the team, which included name, date of birth, position, date of injury, mechanism of injury, and type of injury. In the period of study, 95 injuries were recorded: 42 (44.2\%) were recorded during matches, and $53(55.8 \%)$ during the training period. Injuries occurred more frequently in midfielders and strikers. All injuries happened in the lower limb, most of the injuries were muscular, and most occurred as the result of collisions with other athletes. In summary, this study demonstrates that there is a need for greater safety awareness in the training environment.
\end{abstract}

Keywords: injuries, epidemiology, soccer players

\section{Introduction}

With 220 million players worldwide, soccer is the world's most popular team sport. ${ }^{1,2}$ According to estimates from the Fédération Internationale de Football Association, the average injury costs US\$150, and the total cost of worldwide soccer injuries is nearly $\$ 30$ billion a year. ${ }^{3}$ To reduce this monetary burden, preventive injury programs are of great interest. ${ }^{4}$ In this context, data collection about the epidemiology of injuries, risk factors related to dangerous situations, and aspects of the game are desirable. ${ }^{5}$ Risk factors include intrinsic and extrinsic risk factors. In this context, intrinsic risk factors play an important role, and include previous injury, older age, poor flexibility, and decreased muscle strength or strength imbalances. ${ }^{6}$

In soccer, a player is considered injured when he/she cannot attend the next match or practice session. ${ }^{7}$ According to previous studies, muscle strains, contusions, and sprains constitute approximately $75 \%$ of professional players' injuries. ${ }^{5,8}$ Injuries of the lower limbs, in which the thigh, knee, and ankle are the most commonly impaired sites, ${ }^{1,2,5-8}$ constitute $60 \%-85 \%$ of all soccer injuries in both sexes. More than half of the injuries are caused by collision between players, ${ }^{9,10}$ and most of the others occur during actions such as running, shooting, turning, and heading the ball. ${ }^{1,5}$ Surprisingly, few previous studies have evaluated the occurrence of injury in Brazilian soccer players. Brazil has a high number of participants, and is considered to have some of the best soccer players in the world. Indeed, there is a lack of descriptive data in the international literature concerning this aspect of elite soccer players from South America. submit your manuscript | www.dovepress.com

Dovepress

http://dx.doi.org/10.2/47/OAJSM.S44384 
Thus, the current study was performed to investigate the occurrence of injury in soccer players from a Brazilian premier league professional soccer team. Secondary aims were to describe the mechanisms and specific injury patterns of soccer players in order to enable the development of strategies for injury prevention.

\section{Materials and methods}

The occurrence, site, and cause of injuries were retrospectively studied in 35 male Brazilian professional soccer players from the same team. The squad was composed of three goalkeepers, eight center backs, six wing-/fullbacks, eight defensive midfielders, three attacking midfielders, and seven strikers. The characteristics of the athletes are presented in Table 1.

Data on occurrence, site, and cause of injuries related to the 2009 season, particularly in the Brazilian soccer premier league (played during April to December), were retrospectively collected from medical records. In this period, athletes played 38 official matches. The team had a physician responsible for clinical evaluation, diagnosis, and treatment of injured athletes. This physician, who was present during all training sessions and competitions, was responsible for maintaining the medical records. Information about the injury was noted, including the type, severity, and site of injury; the time and mechanism of injury (traumatic or overuse); and whether it happened during a match or training.

In this study, injury was defined as any physical damage to the player due to soccer-related activity participation that caused the player to miss at least one training session or match. Illnesses, diseases, and mental complaints were not considered physical complaints.

All experimental procedures were designed according to the Helsinki Conference for research on human beings and to the ethical standards in sports-and-exercise science research.

\section{Statistical analysis}

A descriptive statistical analysis was performed (mean, standard deviation, and absolute and relative frequencies) using

Table I Subjects' characteristics $(n=35)$

\begin{tabular}{lc}
\hline & Mean \pm SD \\
\hline Age (years) & $25.7 \pm 4.3$ \\
Body mass $(\mathrm{kg})$ & $79.3 \pm 11.2$ \\
Body fat $(\%)$ & $12.7 \pm 3.5$ \\
Height $(\mathrm{cm})$ & $181.0 \pm 7.0$ \\
\hline
\end{tabular}

Abbreviation: SD, standard deviation.
GraphPad Prism (GraphPad Software, La Jolla, CA, USA) version 5.0 for Windows.

\section{Results}

In the period of study, 95 injuries were recorded: 42 (44.2\%) were recorded during matches, and 53 (55.8\%) during the training period. Data are presented as absolute frequency (relative frequency).

Among the injuries that occurred, five (5.3\%) injuries occurred in goalkeepers (1.66 injuries/athlete), 15 (15.8\%) injuries occurred in center backs ( 1.87 injuries/athlete), eleven (11.6\%) injuries occurred in wing-/fullbacks (1.83 injuries/ athlete), 30 (31.6\%) injuries occurred in defensive midfielders (3.75 injuries/athlete), seven (7.3\%) injuries occurred in attacking midfielders (2.33 injuries/athlete), and 27 (28.4\%) injuries occurred in strikers (3.86 injuries/player).

Most injuries were tendinopathies (27 injuries [28.4\%], 19 during training period and eight during matches), 17 $(17.9 \%)$ were sprains (seven during training period and ten during matches), 14 (14.7\%) were muscle contractures (nine during training period and five during matches), 13 (13.7\%) were myalgias (seven during training period and six during matches), nine (9.4\%) were muscular strains (two during training period and seven during matches), eight (8.4\%) were acute diffuse pain (three during training period and five during matches), two (2.1\%) were periostitis (two during training period and none during matches), one (1.1\%) was bursitis (during training period), one (1.1\%) was a fracture (during training period), one (1.1\%) was synovitis (during training period), and two (2.1\%) were other injuries (one during training period and one during matches). All injuries occurred in the lower limb.

Finally, regarding the mechanism of injury, 23 (24.2\%) injuries occurred as a result of collisions with other athletes, $19(20.0 \%)$ injuries as a result of twisting the knee with the foot planted firmly on the ground, $15(15.8 \%)$ as a result of running activities, twelve $(11.7 \%)$ as a result of kicking activities, eight (8.4\%) as a result of jumping activities, six $(6.3 \%)$ as a result of ball-crossing activities, five (5.2\%) as a result of an abrupt stop, four (4.2\%) as a result of falls, two $(2.1 \%)$ as a result of lateral movements, one (1.1\%) during dribbling, and one (1.1\%) during heading.

\section{Discussion}

Since injury in soccer represents a serious problem in terms of health and performance for players and clubs, the purpose of the present study was to describe briefly the number of injuries in a Brazilian professional soccer team from the 
premier league. The results of this study suggest that injuries are more prevalent during the training period and occurred most frequently in midfielders and strikers. Collisions with other athletes were referenced as the main mechanism of injury. In addition, most of the injuries were tendinopathies and sprains (ligamentous disruption).

Regarding the injury sites, lower limbs were involved in all injuries described in this study. These findings have been reported in previous studies. ${ }^{1,11}$ Indeed, injuries of the lower limbs, in which the thigh, knee, and ankle are the most commonly impaired sites, ${ }^{1,2,5-8}$ constitute $60 \%-85 \%$ of all soccer injuries in both sexes. These findings are most likely associated with improper use of protective equipment during training, insufficient preseason preparation, sudden movements without proper warm-up, or insufficient knowledge of team members or type and volume of exercise. $^{7,12,13}$

Injury occurrence during the training period was greater than during matches. There are two possible explanations for this finding: (1) much more time is spent training than playing in matches, or (2) the training regimen in soccer is characterized by overexertion (this is reflective of a higher emphasis on match-specific speed, power, and agilityconditioning drills undertaken in the training sessions).

A closer look at injury mechanisms is required for further investigations. Most of the studies did not distinguish between contact and noncontact injury patterns. In the present study, most injuries occurred as a result of collisions with other athletes. This result is in line with previous studies. ${ }^{12,14}$ In the study of mechanisms of injuries in the English Premier League, the most frequent contacts that led to injury were the results of being tackled, tackling, and being charged. ${ }^{5}$ In order to reduce incidence and severity of contact injuries, more intense enforcement of rules by referees ${ }^{9}$ and more emphasis on proper usage of protective measures could be effective. ${ }^{3}$ By better planning of strength and proprioceptive exercises and also improving performance techniques, the incidence of noncontact injuries may be reduced.

Our results concerning the frequency of injuries in the six player positions (goalkeepers, center backs, wing-/ fullbacks, defensive midfielders, attacking midfielders, and strikers) are in accordance with previous studies, ${ }^{7,14}$ because in this study, the highest number of injuries occurred in the strikers and defensive players. This result may be explained by considering the new style of soccer: strength, speed, and especially directional changes at high acceleration predispose both attack and defense players to injuries and increase the possibility of collisions with opponents.

This study demonstrates that there is a need for greater safety awareness in the training environment. A trained sports physician was available for this team, but not all teams have access to this level of medical support. In addition, an understanding of the demands of training and the effects that injuries have on players is essential for the identification of injury-prevention strategies. Finally, further studies must be conducted to clarify the relationship between injuries and field conditions.

\section{Acknowledgment}

We are grateful to the directors of Grêmio Barueri Futebol LTDA.

\section{Disclosure}

The authors report no conflicts of interest in this work.

\section{References}

1. Emery CA, Meeuwisse WH, Hartmann SE. Evaluation of risk factors for injury in adolescent soccer: implementation and validation of an injury surveillance system. Am J Sports Med. 2005;33:1882-1891.

2. Kucera KL, Marshall SW, Kirkendall DT, Marchak PM, Garrett WE Jr. Injury history as a risk factor for incident injury in youth soccer. Br J Sports Med. 2005;39:462.

3. Giza E, Micheli JL. Soccer injuries. In: Maffulli N, Caine DJ, editors. Epidemiology of Pediatric Sports Injuries: Team Sports. Basel: Karger; 2005:140-169.

4. Dupont G, Nedelec M, McCall A, McCormack D, Berthoin S, Wisløff U. Effect of 2 soccer matches in a week on physical performance and injury rate. Am J Sports Med. 2010;38:1752-1758.

5. Rahnama N, Reilly $\mathrm{T}$, Lees A. Injury risk associated with playing actions during competitive soccer. Br J Sports Med. 2002;36:345-359.

6. Hägglund M, Waldén M, Ekstrand J. Risk factors for lower extremity muscle injury in professional soccer: the UEFA Injury Study. Am J Sports Med. 201;41:327-335.

7. Junge A, Dvorak J. Influence of definition and data collection on the incidence of injuries in football. Am J Sports Med. 2000;28:S40-S46.

8. Wong P, Hong Y. Soccer injury in the lower extremities. Br J Sports Med. 2005;39:473-482.

9. Dvorak J, Junge A, Grimm K, Kirkendall D. Medical report from the 2006 FIFA World Cup Germany. Br J Sports Med. 2007;41:578-581.

10. Junge A, Langevoort G, Pipe A, et al. Injuries in team sport tournaments during the 2004 Olympic Games. Am J Sports Med. 2006;34: $565-576$.

11. Zanuto EA, Harada H, Gabriel-Filho LR. Epidemiological assessment of injuries and physical profile of amateur soccer players in the western region of São Paulo. Rev Bras Med Esporte. 2010;16:116-120.

12. Faude O, Junge A, Kindermann W, Dvorak J. Injuries in female soccer players: a prospective study in the German national league. Am J Sports Med. 2005;33:1694-1700.

13. Morgan BE, Oberlander MA. An examination of injuries in major league soccer. The inaugural season. Am J Sports Med. 2001;29:426-430.

14. Engström B, Johansson C, Törnkvist H. Soccer injuries among elite female players. Am J Sports Med. 1991;19:372-375. 


\section{Publish your work in this journal}

Open Access Journal of Sports Medicine is an international, Visit http://www.dovepress.com/testimonials.php to read real quotes peer-reviewed, open access journal publishing original research, from published authors.

reports, reviews and commentaries on all areas of sports

medicine. The manuscript management system is completely

online and includes a very quick and fair peer-review system.

Submit your manuscript here: http://www.dovepress.com/open-access-journal-of-sports-medicine-journal 